\title{
Prognostic factors associated with pain palliation after spine stereotactic body radiation therapy
}

\author{
Varun Puvanesarajah, BS, ${ }^{1}$ Sheng-fu Larry Lo, MD, MHS, ${ }^{1}$ Nafi Aygun, MD, ${ }^{2}$ Jason A. Liauw, MD, ${ }^{1}$ \\ Ignacio Jusué-Torres, MD, Ioan A. Lina, BS, ${ }^{1}$ Uri Hadelsberg, BS, ${ }^{3}$ Benjamin D. Elder, MD, PhD, ${ }^{1}$ \\ Ali Bydon, MD, ${ }^{1}$ Chetan Bettegowda, MD, PhD, ${ }^{1}$ Daniel M. Sciubba, MD, ${ }^{1}$ Jean-Paul Wolinsky, MD, ${ }^{1}$ \\ Daniele Rigamonti, MD, ${ }^{1}$ Lawrence R. Kleinberg, MD, ${ }^{3}$ Ziya L. Gokaslan, MD, ${ }^{1}$ \\ Timothy F. Witham, MD, ${ }^{1}$ Kristin J. Redmond, MD, MPH, ${ }^{3}$ and Michael Lim, MD'
}

Departments of ${ }^{1}$ Neurosurgery, ${ }^{2}$ Radiology, and ${ }^{3}$ Radiation Oncology and Molecular Radiation Science, Johns Hopkins University School of Medicine, Baltimore, Maryland

OBJECT The number of patients with spinal tumors is rapidly increasing; spinal metastases develop in more than $30 \%$ of cancer patients during the course of their illness. Such lesions can significantly decrease quality of life, often necessitating treatment. Stereotactic radiosurgery has effectively achieved local control and symptomatic relief for these patients. The authors determined prognostic factors that predicted pain palliation and report overall institutional outcomes after spine stereotactic body radiation therapy (SBRT).

METHODS Records of patients who had undergone treatment with SBRT for either primary spinal tumors or spinal metastases from June 2008 through June 2013 were retrospectively reviewed. Data were collected at the initial visit just before treatment and at 1-, 3-, 6-, and 12-month follow-up visits. Collected clinical data included Karnofsky Performance Scale scores, pain status, presence of neurological deficits, and prior radiation exposure at the level of interest. Radiation treatment plan parameters (dose, fractionation, and target coverage) were recorded. To determine the initial extent of epidural spinal cord compression (ESCC), the authors retrospectively reviewed MR images, assessed spinal instability according to the Bilsky scale, and evaluated lesion progression after treatment.

RESULTS The study included 99 patients (mean age 60.4 years). The median survival time was 9.1 months $(95 \% \mathrm{Cl}$ $6.9-17.2$ months). Significant decreases in the proportion of patients reporting pain were observed at 3 months ( $p<$ $0.0001), 6$ months $(p=0.0002)$, and 12 months $(p=0.0019)$ after treatment. Significant decreases in the number of patients reporting pain were also observed at the last follow-up visit $(p=0.00020)$ (median follow-up time 6.1 months, range 1.0-56.6 months). Univariate analyses revealed that significant predictors of persistent pain after intervention were initial ESCC grade, stratified by a Bilsky grade of $1 c(p=0.0058)$; initial American Spinal Injury Association grade of $D(p$ $=0.011)$; initial Karnofsky Performance Scale score, stratified by a score of $80(p=0.002)$; the presence of multiple treated lesions $(p=0.044)$; and prior radiation at the site of interest $(p<0.0001)$. However, when multivariate analyses were performed on all variables with $p$ values less than 0.05 , the only predictor of pain at last follow-up visit was a prior history of radiation at the site of interest $(p=0.0038)$, although initial ESCC grade trended toward significance $(p=0.073)$. Using pain outcomes at 3 months, at this follow-up time point, pain could be predicted by receipt of radiation above a threshold biologically effective dose of $66.7 \mathrm{~Gy}$.

CONCLUSIONS Pain palliation occurs as early as 3 months after treatment; significant differences in pain reporting are also observed at 6 and 12 months. Pain palliation is limited for patients with spinal tumors with epidural extension that deforms the cord and for patients who have previously received radiation to the same site. Further investigation into the optimal dose and fractionation schedule are needed, but improved outcomes were observed in patients who received radiation at a biologically effective dose (with an $\alpha / \beta$ of 3.0) of 66.7 Gy or higher.

http://thejns.org/doi/abs/10.3171/2015.2.SPINE14618

KEY WORDS stereotactic; radiotherapy; SBRT; oncology; pain palliation

\footnotetext{
ABBREVIATIONS ASIA = American Spinal Injury Association; BED = biologically effective dose; ECOG = Eastern Cooperative Oncology Group; ESCC = epidural spinal cord compression; KPS = Karnofsky Performance Scale; SBRT = stereotactic body radiation therapy.

SUBMITTED June 25, 2014. ACCEPTED February 18, 2015

INCLUDE WHEN CITING Published online July 31, 2015; DOI: 10.3171/2015.2.SPINE14618.

DISCLOSURE Dr. Lim is a consultant and speaker for Accuray. Dr. Gokaslan owns stock in US Spine and Spinal Kinetics. Dr. Sciubba is a consultant for Medtronic,

DePuy, Globus, and NuVasive. Dr. Witham has received non-study related support from Eli Lilly Pharmaceuticals.

* Drs. Lim and Redmond share senior authorship for this manuscript.
} 
$\mathrm{T}$ He number of patients with spinal tumors of either primary or metastatic origin is rapidly increasing; spinal metastases develop in more than $30 \%$ of cancer patients during the course of their illness. ${ }^{28,41}$ In this patient population, spinal lesions are a common source of decreased quality of life, secondary to increased bone pain or frank epidural spinal cord compression (ESCC) that can result in permanent neurological deficits. ${ }^{17,19,29}$ Although symptoms are managed with steroid and/or analgesic use, progressive tumor growth often necessitates local therapy.

Surgical decompression and/or stabilization is the standard of care for patients with malignant epidural spinal cord compression from solid tumors or tumors resistant to conventional external-beam radiation. ${ }^{29,38}$ External-beam therapy represents an alternative noninvasive technique that has historically been performed in patients who are not considered surgical candidates because of poor performance status, extensive systemic disease, or concurrent medical conditions or in patients who have radiosensitive tumors, such as hematological malignancies. Unfortunately, control rates after conventional radiation therapy are not ideal for most solid tumors because the radiation dose must be limited to respect the tolerance of the spinal cord and other adjacent structures. ${ }^{11}$

Recently, spine stereotactic body radiation therapy (SBRT) has been used to precisely deliver radiation, allowing for dose escalation and improved local control while limiting the dose to the adjacent normal structures and spinal cord. ${ }^{1,4,12,15,16,25,32,33} \mathrm{~A}$ recent meta-analysis reported a local control rate of $92 \%$ and symptomatic relief for $82 \%$ of patients. ${ }^{20}$

Although spine SBRT is accepted as a safe and effective noninvasive treatment alternative for spinal metastases, many questions remain. For example, although spine SBRT is generally accepted for patients with oligometastatic disease, its role for patients with advanced disease is controversial. Similarly, the optimal dose and fractionation schedule remain uncertain. The purpose of this study was to review outcomes in a heterogeneous cohort of patients with advanced metastatic disease treated with spine SBRT at a single institution. Our intent was to determine prognostic factors that predicted pain palliation and to report overall institutional outcomes.

\section{Methods}

Records of patients who underwent spine SBRT for either primary spinal tumors or spinal metastases from June 2008 through June 2013 were retrospectively reviewed. Patients were excluded if they received treatment for intramedullary lesions. All patients had undergone initial evaluation that included a neurological exam, pain assessment, and imaging confirmation of a spinal lesion.

\section{Data Collection}

Details recorded from the medical record reviews were general demographics, oncological history, treatment history, clinician assessments, and medication use. Disease location was confirmed via cross-referencing MR images, CT images, and radiographs with radiologist-written notes. The radiation treatment plan parameters of dose, fractionation, and target coverage were also recorded. Ra- diation fractionation schemes were converted to biologically effective doses (BEDs) with an $\alpha / \beta$ of 3.0.

Functional status was assessed by using the Karnofsky Performance Scale (KPS). For most patients, either a KPS score or an Eastern Cooperative Oncology Group (ECOG) score was provided by the oncologist responsible for patient assessment before SBRT. When only an ECOG score was provided, ECOG scores were converted to KPS scores by using pertinent clinical patient information and the following approximate conversion, which has been validated in a large sample of lung cancer patients: ECOG scores of $0-1,2$, and 3-4 are roughly equivalent to KPS scores of 80-100,60-70, and 10-50, respectively. For patients for whom neither ECOG nor KPS scores were provided, an estimate was obtained from clinical records, particularly clinician-acquired social histories that determined the extent of functional independence exhibited by the patient in question. For these patients, functional status was retrospectively evaluated independently by 2 evaluators, and the final KPS score was reported as the average of these 2 scores.

The primary outcome was the presence of pain corresponding with the spine radiosurgery target. Pain was scored in a binary fashion. In terms of determining improvement in pain, successful pain treatment was defined as patient-reported complete remission of previous pain at the treatment level, a pain score of 0 , or recurrent pain that could no longer be attributable to the lesion of interest. Initial use of narcotics, another measure of pain, was recorded as the prescription of narcotics, either as needed or scheduled. Neurological status was assessed by using the American Spinal Injury Association (ASIA) Impairment Scale, which assigns patients with spinal lesions to letter categories from A (total loss of neurological function below the level of interest) to $\mathrm{E}$ (absence of functional deficits). For this study, patients who were evaluated as having 5/5 strength in all pertinent muscle groups as well as intact sensation and touch were deemed to have ASIA Grade E status. Neurological status was assigned only if performance of a neurological examination by a boardcertified neurologist, radiation oncologist, or neurosurgeon was documented. These parameters were assessed at approximately $1,3,6$, and 12 months and at the last documented clinical visit.

When medical records were incomplete, survival time was determined by using the Social Security Death Index Master File. For patients lost to follow-up and for whom death was not noted in the Social Security Death Index Master File, dates corresponding to the last clinical visit were used as last follow-up.

\section{Imaging}

One board-certified neuroradiologist (N.A.) assessed the extent of ESCC in all cervical and thoracic lesions by reviewing available images taken before SBRT. ESCC was evaluated according to the 6-point scale popularized by Bilsky et al. in 2010. ${ }^{3}$ This scale relies on the use of axial T2-weighted MR images to judge the extent of extraosseous tumor growth and thecal sac compression. The 6 grades $(0,1 \mathrm{a}, 1 \mathrm{~b}, 1 \mathrm{c}, 2$, and 3$)$ were assigned as follows: Grade 0 indicates disease that is contained in a vertebral 
body without any epidural impingement; Grade 1 indicates disease that extends outside of the vertebral body with subarachnoid space impingement in the absence of spinal cord deformation; Grade 2 indicates disease with epidural extension that partially deforms the spinal cord without completely obliterating the subarachnoid space; and Grade 3 indicates spinal cord deformation such that no CSF is visible at the level of interest. Grade 1 was further subdivided into 1a (epidural impingement without deformation of the thecal sac, $1 \mathrm{~b}$ (epidural impingement with deformation of the thecal sac but without spinal cord abutment), and 1c (deformation of the thecal sac with spinal cord abutment). For the purposes of analysis, for patients with multiple cervical and/or thoracic lesions, we considered tabulated ESCC values to correspond with the highest such value among the lesions. For example, for a patient with a T-5 ESCC of Grade $1 \mathrm{~b}$ and a T-10 ESCC of Grade 2, a value of 2 was tabulated.

Lesions that had been appropriately followed up with MRI were further analyzed for evidence of local progression. Local progression was assessed by the presence of either progressive canal narrowing on serial MR images or evidence of tumor growth. If results of a single scanning session were indeterminate, serial scanning was used to determine tumor growth. The date of progression was backdated to the date of the first indeterminate scan. Additional radiographic analysis included serial detection of compression fractures, before and after radiosurgery. This latter analysis was limited to patients who did not undergo additional decompressive surgery. Data pertaining to treatment with vertebroplasty or kyphoplasty were also acquired.

\section{Statistical Analysis}

Overall survival times after SBRT were assessed by using Kaplan-Meier estimates. The McNemar test was used to determine significant changes in the proportion of patients experiencing pain at each time point compared with that at initial presentation. The logistic regression model was used to assess determinants of eventual treatment failure at the 3-month time point, as assessed by presence of pain. Odds ratios and 95\% confidence intervals were also computed by using this method. Fitted values of pain at the 3-month time point obtained from the logistic regression analysis of radiation doses were used to obtain a threshold radiation dose that predicted treatment success. Statistical analyses were performed by using STATA 11.0 (StataCorp, LP) and R version 3.0.2 (R Core Team). Significance was established when comparisons resulted in probability values less than or equal to 0.05 .

\section{Results}

\section{Demographics and Initial Clinical Presentation}

A total of 99 patients (mean age 60.4 years) were included in this study. Tumor information is provided in Table 1. Patient demographics and initial clinical presentation information are summarized in Table 2. At the time of SBRT, 47 patients had concomitant metastases of the brain, liver, lung, or kidney, and 51 had extraspinal osseous metastases.
TABLE 1. Tumor locations and histological types

\begin{tabular}{lc}
\hline \multicolumn{1}{c}{ Characteristic } & No. of Lesions/Patients \\
\hline Tumor location & 22 \\
\hline Cervical & 60 \\
\hline Thoracic & 43 \\
\hline Lumbar & 5 \\
\hline Sacrum & 1 \\
\hline Coccyx & 131 \\
\hline Total & \\
\hline Histological type & 18 \\
\hline Renal cell carcinoma & 12 \\
\hline Breast & 10 \\
\hline Prostate & 8 \\
\hline Non-small cell lung carcinoma & 7 \\
\hline Sarcoma & 6 \\
\hline Colon & 5 \\
\hline Chordoma & 4 \\
\hline Melanoma & 4 \\
\hline Nasopharyngeal & 3 \\
\hline Pancreas & 3 \\
\hline Urothelial & 3 \\
\hline Atypical pulmonary carcinoid & 16 \\
\hline Other & 99 \\
\hline Total &
\end{tabular}

At the time of presentation, 79 patients reported pain and 49 reported use of narcotics, on either an as-needed or daily-dose basis. A total of 73 were classified as ASIA Grade E, with no motor or sensory deficits. For 60 patients, bony cervical or thoracic lesions were present and initial T2-weighted MR images were available for review; most $(51.7 \%)$ of these patients exhibited disease that did not contact the spinal cord, garnering a Bilsky grade of 0 , $1 \mathrm{a}$, or $1 \mathrm{~b}$. The patient with Bilsky Grade 3 disease underwent concomitant surgical decompression.

\section{Survival Times}

The median survival time for the overall cohort was 9.1 months (95\% CI 6.9-17.2 months) (Fig. 1). The percentage of patients who survived 1 year was $43.7 \%$.

\section{Pain Improvement}

The proportion of patients who reported local pain at the site of treatment consistently declined from initial presentation to 6 months after SBRT (Fig. 2). However, the proportion who reported local pain increased slightly at 12 months. Narcotic use exhibited a similar trend, although the proportion of patients taking a daily dose of narcotics was lower at 12 months than at any previous time point. When follow-up information was available at a given time point, it was compared with initial presentation information for the same patients. Significant decreases in the proportion of patients reporting pain were observed at 3 months $(p<0.0001), 6$ months $(p=0.0002)$, and 12 months $(p=0.0019)$ after treatment. Significant 
TABLE 2. Characteristics of 99 patients

\begin{tabular}{|c|c|}
\hline Characteristic/Category & Total \\
\hline Mean age (SD) & $60.4(12.1)$ \\
\hline \multicolumn{2}{|l|}{ Sex } \\
\hline M & 51 \\
\hline $\mathrm{F}$ & 48 \\
\hline \multicolumn{2}{|l|}{ Initial pain } \\
\hline No & 20 \\
\hline Yes & 79 \\
\hline \multicolumn{2}{|l|}{ Initial narcotic use* } \\
\hline No & 50 \\
\hline Yes & 49 \\
\hline \multicolumn{2}{|l|}{ Initial ASIA grade } \\
\hline D & 26 \\
\hline$E$ & 73 \\
\hline \multicolumn{2}{|l|}{ Initial ESCC score } \\
\hline 0 & 13 \\
\hline $1 a$ & 6 \\
\hline $1 b$ & 12 \\
\hline $1 \mathrm{c}$ & 6 \\
\hline 2 & 22 \\
\hline 3 & 1 \\
\hline Total & 60 \\
\hline \multicolumn{2}{|l|}{ Initial KPS score } \\
\hline $80-100$ & 67 \\
\hline $50-70$ & 31 \\
\hline $0-40$ & 1 \\
\hline \multicolumn{2}{|l|}{ Decompressive surgery } \\
\hline No & 67 \\
\hline Yes & 32 \\
\hline \multicolumn{2}{|l|}{ Previous radiotherapy } \\
\hline No & 59 \\
\hline Yes & 40 \\
\hline \multicolumn{2}{|l|}{ Other metastases } \\
\hline \multicolumn{2}{|l|}{ Visceral } \\
\hline 0 & 52 \\
\hline 1 & 47 \\
\hline \multicolumn{2}{|l|}{ Skeletal (not spine) } \\
\hline 0 & 48 \\
\hline 1 & 51 \\
\hline
\end{tabular}

* As needed or daily dose.

decreases in the number of patients reporting pain were also observed at the last follow-up visit. Final follow-up analysis was available for 77 patients, 34 (44.2\%) of whom reported pain at the last clinical visit (median follow-up time 6.1 months, range 1.0-56.6 months), a significant improvement over initial presentation $(\mathrm{p}=0.0002)$ (Table 3$)$.

\section{Imaging Control}

Follow-up MR images that could be analyzed for the presence of local recurrence were available for 39 patients with 52 lesions (median follow-up time 6.03 months, range

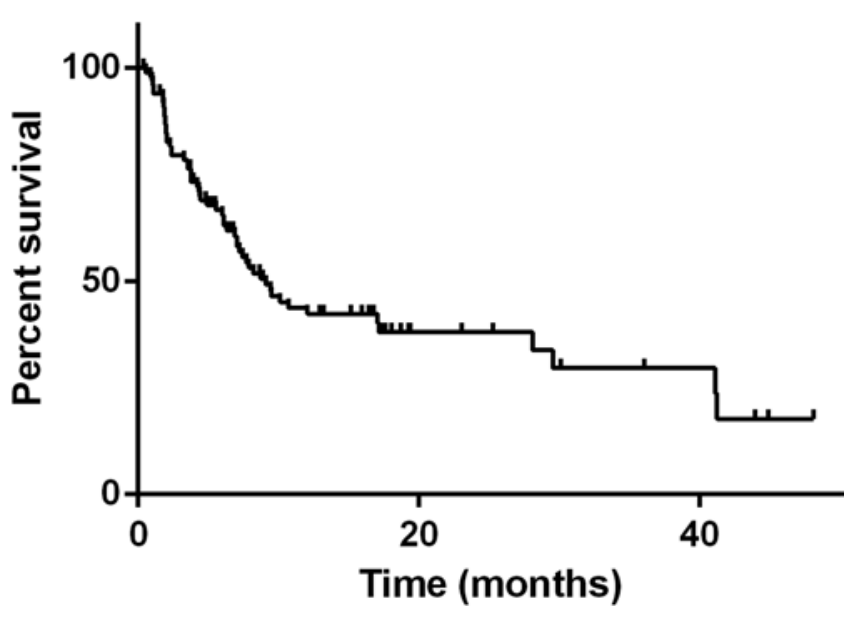

FIG. 1. Kaplan-Meier survival curve. Median survival time is 8.7 months.

1.1-42.9 months). Of these lesions, 11 (21.1\%) exhibited local progression through increased canal narrowing or progressive growth.

\section{Treatment Failure}

For 4 patients, surgery was emergently performed after purported radiosurgery failure. For all 4 , the indication for surgery was development of intractable back pain resulting from tumor progression and resultant mechanical instability. For 2 of these 4 patients, neurological deficits also developed before surgery.

By using the presence of pain at 3 months as an outcome, predictors of treatment failure were analyzed (Table 4). Univariate analysis indicated that the following were significant predictors of persistent pain after intervention: initial ESCC grade, stratified by a Bilsky grade of $1 \mathrm{c}(\mathrm{p}=$ $0.0058)$; initial ASIA grade of $\mathrm{D}(\mathrm{p}=0.011)$; initial KPS score, stratified by a score of $80(\mathrm{p}=0.002)$; the presence of multiple treated lesions $(\mathrm{p}=0.044)$; and prior radiation at the site of interest ( $p<0.0001)$. However, when multivariate analysis was performed on all variables with $p$ values less than 0.05 , the only predictor of pain at last follow-up visit was a prior history of radiation at the site of interest $(\mathrm{p}=0.0038)$, although initial ESCC grade trended toward significance $(\mathrm{p}=0.073)$.

\section{Radiation Dosage}

The radiation fractionation schemes used in this patient population are summarized in Table 5. The median

\section{TABLE 3. Pain reported over time}

\begin{tabular}{|c|c|c|c|c|}
\hline \multirow{2}{*}{$\begin{array}{c}\text { Time After } \\
\text { Treatment } \\
\text { (mos) }\end{array}$} & \multicolumn{3}{|c|}{ No. of Patients } & \multirow[b]{2}{*}{$\begin{array}{c}\text { McNemar } \\
\text { p Value }\end{array}$} \\
\hline & Evaluated & $\begin{array}{l}\text { Reporting } \\
\text { Pain Initially }\end{array}$ & $\begin{array}{l}\text { Reporting Pain } \\
\text { During Follow-Up }\end{array}$ & \\
\hline 1 & 52 & 37 & 30 & 0.096 \\
\hline 3 & 62 & 47 & 26 & 0.000072 \\
\hline 6 & 46 & 33 & 14 & 0.00017 \\
\hline 12 & 27 & 22 & 9 & 0.0019 \\
\hline $\begin{array}{l}\text { Last follow- } \\
\quad \text { up }\end{array}$ & 77 & 57 & 34 & 0.00020 \\
\hline
\end{tabular}


A

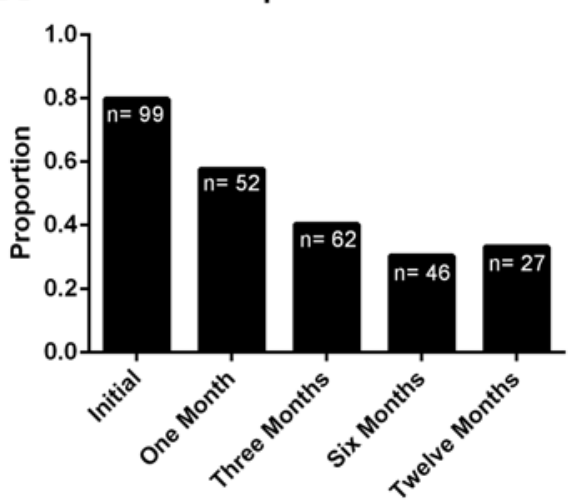

B

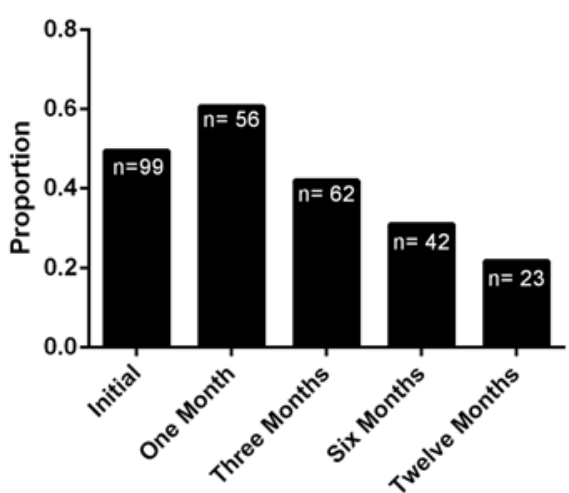

C

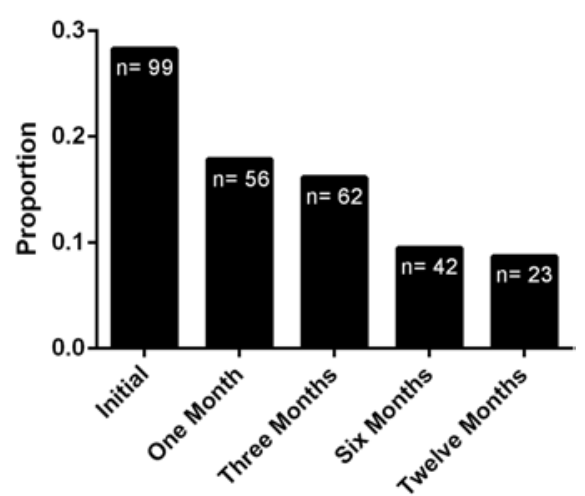

FIG. 2. Trends in reported pain (A), narcotic usage (B), and steroid use (C).

dose prescribed was 21 Gy (range 6-54.9 Gy) delivered in a median of 3 fractions (range 1-33); median BED was 66.7 Gy. Whether the patient had received prior radiation at the level of interest was significantly associated with the final BED. Patients who had not received prior radia- tion received a mean BED of 79.0 Gy $(95 \%$ CI 73.7-84.3 $\mathrm{Gy}$ ), and those who had received prior radiation received a mean BED of 60.6 Gy (95\% CI 56.3-64.8 Gy) ( $p<0.0001)$. The fitted values from the logistic regression analysis of pain at 3 months versus radiation dose showed that the

TABLE 4. Analysis of variables predictive of treatment success*

\begin{tabular}{|c|c|c|c|c|c|c|}
\hline \multirow[b]{2}{*}{ Variable } & \multicolumn{2}{|c|}{ Treatment Failure at Last FU } & \multicolumn{3}{|c|}{ Univariate Analysis } & \multirow{2}{*}{$\frac{\text { Multivariate Analysis }}{\mathrm{p} \text { Value }}$} \\
\hline & No & Yes & OR & $95 \% \mathrm{Cl}$ & $p$ Value & \\
\hline Age & & & 1.33 & $0.45-3.93$ & 0.61 & $\mathrm{NI}$ \\
\hline$<65$ & 26 & 16 & & & & \\
\hline$\geq 65$ & 11 & 9 & & & & \\
\hline Initial ESCC score & & & 9.56 & $2.09-54.17$ & 0.0058 & 0.073 \\
\hline $0-1 \mathrm{~b}$ & 17 & 4 & & & & \\
\hline $1 c-3$ & 4 & 9 & & & & \\
\hline Initial ASIA grade & & & 0.18 & $0.044-0.64$ & 0.011 & 0.89 \\
\hline D & 4 & 10 & & & & \\
\hline$E$ & 33 & 15 & & & & \\
\hline Initial KPS score & & & 0.14 & $0.039-0.47$ & 0.0020 & 0.32 \\
\hline$<80$ & 5 & 13 & & & & \\
\hline$\geq 80$ & 32 & 12 & & & & \\
\hline No. of treated lesions & & & 3.6 & $1.07-13.44$ & 0.044 & 0.39 \\
\hline 1 & 32 & 16 & & & & \\
\hline$>1$ & 5 & 9 & & & & \\
\hline Decompressive surgery & & & 2.87 & $0.98-8.76$ & 0.057 & $\mathrm{NI}$ \\
\hline No & 28 & 13 & & & & \\
\hline Yes & 9 & 12 & & & & \\
\hline Previous radiotherapy & & & 13.29 & $4.10-49.66$ & 0.000041 & 0.0038 \\
\hline No & 31 & 7 & & & & \\
\hline Yes & 6 & 18 & & & & \\
\hline Visceral lesions & & & 0.83 & $0.30-2.30$ & 0.72 & $\mathrm{NI}$ \\
\hline No & 19 & 14 & & & & \\
\hline Yes & 18 & 11 & & & & \\
\hline Other skeletal lesions & & & 1.59 & $0.57-4.48$ & 0.38 & $\mathrm{NI}$ \\
\hline No & 22 & 12 & & & & \\
\hline Yes & 15 & 13 & & & & \\
\hline
\end{tabular}

$\mathrm{FU}=$ follow-up; $\mathrm{NI}=$ not included.

* Boldface indicates statistical significance. 
TABLE 5. Summary of radiation dosages

\begin{tabular}{|c|c|c|}
\hline $\begin{array}{l}\text { Prescription Dose } \\
\text { (total radiation/fractions) }\end{array}$ & BED (Gy) & No. of Lesions \\
\hline $6 / 1$ & 18 & 2 \\
\hline $10 / 2$ & 26.7 & 1 \\
\hline $10 / 1$ & 43.3 & 3 \\
\hline $12 / 1$ & 60 & 7 \\
\hline $14 / 2$ & 46.7 & 3 \\
\hline $14 / 1$ & 79.3 & 4 \\
\hline $15 / 3$ & 40 & 5 \\
\hline $15 / 1$ & 90 & 1 \\
\hline $15 / 6$ & 27.5 & 2 \\
\hline $16 / 2$ & 58.9 & 1 \\
\hline $16 / 1$ & 101.3 & 8 \\
\hline $16 / 4$ & 37.3 & 1 \\
\hline $18 / 1$ & 126 & 6 \\
\hline $18 / 3$ & 54 & 9 \\
\hline $20 / 4$ & 53.3 & 2 \\
\hline $20 / 5$ & 46.7 & 3 \\
\hline $21 / 3$ & 70 & 28 \\
\hline $24 / 3$ & 88 & 3 \\
\hline $25 / 5$ & 66.7 & 28 \\
\hline $30 / 5$ & 90 & 13 \\
\hline $35 / 5$ & 116.7 & 1 \\
\hline Total & Not applicable & 131 \\
\hline
\end{tabular}

median value of 66.7 Gy when used as a cutoff value had a predicted probability of pain at 3 months of 0.49 . After radiation doses were dichotomized by this threshold, presence of pain at 3 months differed significantly between the 2 groups (OR $0.30,95 \%$ CI $0.01-0.83)$ ( $\mathrm{p}=0.02$ ), and a significant association was found between radiation dose and the presence of pain at 3 months $(p=0.012)$ (Fig. 3).

The association between radiographic canal impingement before treatment and BED trended toward significance among patients with Bilsky grades of $0-1 \mathrm{~b}$ who received an average BED of 71.0 (95\% CI 64.4-77.5 Gy) and patients with Bilsky grades of $1 \mathrm{c}-3$ who received an average BED of 63.4 Gy (95\% CI 59.0-67.9 Gy) ( $\mathrm{p}=0.0874)$.

The median maximum radiation dose to the spinal cord, thecal sac, or cauda equina was 16.4 Gy (range 0.6-42.8 Gy).

\section{Complications}

Among patients who did not undergo adjunctive surgical decompression, 6 (7.0\% of lesions treated with SBRT only) de novo compression fractures occurred at treated levels for 5 patients. Of these 5 patients, 4 reported pain, which led to the discovery of the compression fractures, and the other patient, who had 2 simultaneously discovered compression fractures, was largely asymptomatic. Prior radiation to the affected level had been received by 2 of these 5 patients. These compression fractures were first documented at a median of 3.3 months (range 1-11.6 months) after initiation of SBRT. An additional patient experienced a compression fracture between fractions of her radiation treatment, prob- ably because of preexisting structural weakness. Of the remaining lesions in the entire pool of patients, at least 37 (29.3\%) demonstrated partial compression fracture or loss of vertebral height before treatment.

In total, 6 patients underwent vertebroplasty before SBRT, and another 4 patients underwent vertebroplasty for preexisting compression fractures after SBRT.

No radiation-induced myelopathy developed in any patient.

\section{Discussion}

Spinal metastases develop in 30\%-90\% of cancer patients at some point during their disease course. ${ }^{9,23,36,41}$ For some patients, these lesions are sometimes discovered during routine staging workups; but others experience pain or neurological deficits, ${ }^{27}$ pain from compression of neural structures, or functional neurological compromise secondary to epidural extension. ${ }^{29,31}$ Although visceral metastases have a larger effect than spinal metastases on survival times,${ }^{37}$ the resulting decreases in quality of life have encouraged the development of new techniques to effectively manage spinal metastases. ${ }^{24}$

Stereotactic radiosurgery is a well-accepted noninvasive method of managing spine lesions, and many studies have evaluated its efficacy. ${ }^{1,8,12-15,18,21,30,34,40,42}$ Previous studies have frequently included patients who survived more than 1 year after SBRT, and performance status distributions were generally favorable (Table 6). Additionally, in these studies, many patients underwent SBRT for disease recurrence after prior conventional radiation to the same level. As such, it is difficult to infer from these studies whether critically ill patients would still benefit from firstline radiosurgical intervention, particularly given their limited overall survival times. Our study included patients with a median survival time of 9.1 months and an actuarial 1-year survival rate of $43.7 \%$. Additionally, patients often showed signs of advanced metastatic disease, and $53 \%$ had visceral metastases at the time of radiosurgery.

At last follow-up visit, 55.8\% of patients were without local back pain attributable to vertebral body lesions. This finding is consistent with that of a study by Wang et al. that used a similar pain palliation metric as an outcome variable. ${ }^{40}$ In that study, 6 months after SBRT, the proportion of patients reporting no pain increased from $26 \%$ initially to $54 \%,{ }^{40}$ a time that is comparable to our median final follow-up time of 6.1 months. Additionally, in our series, the proportion of patients reporting pain decreased significantly at 3, 6, and 12 months after radiosurgery. Although pain decreased significantly at these time points, the proportion of patients using narcotics and steroids did not decrease. These conflicting results may be the result of development of pain at other sites associated with increased disease or possibly the slow tapering of a steroidal medication dosage, the latter of which was not directly assessed in this study.

In our heterogeneous cohort, absence of local vertebral pain at 3 months after treatment was determined by whether radiation had previously been delivered to that level. Another predictor that trended toward significance was radiographic canal impingement $(\mathrm{p}<0.10)$. With respect to 

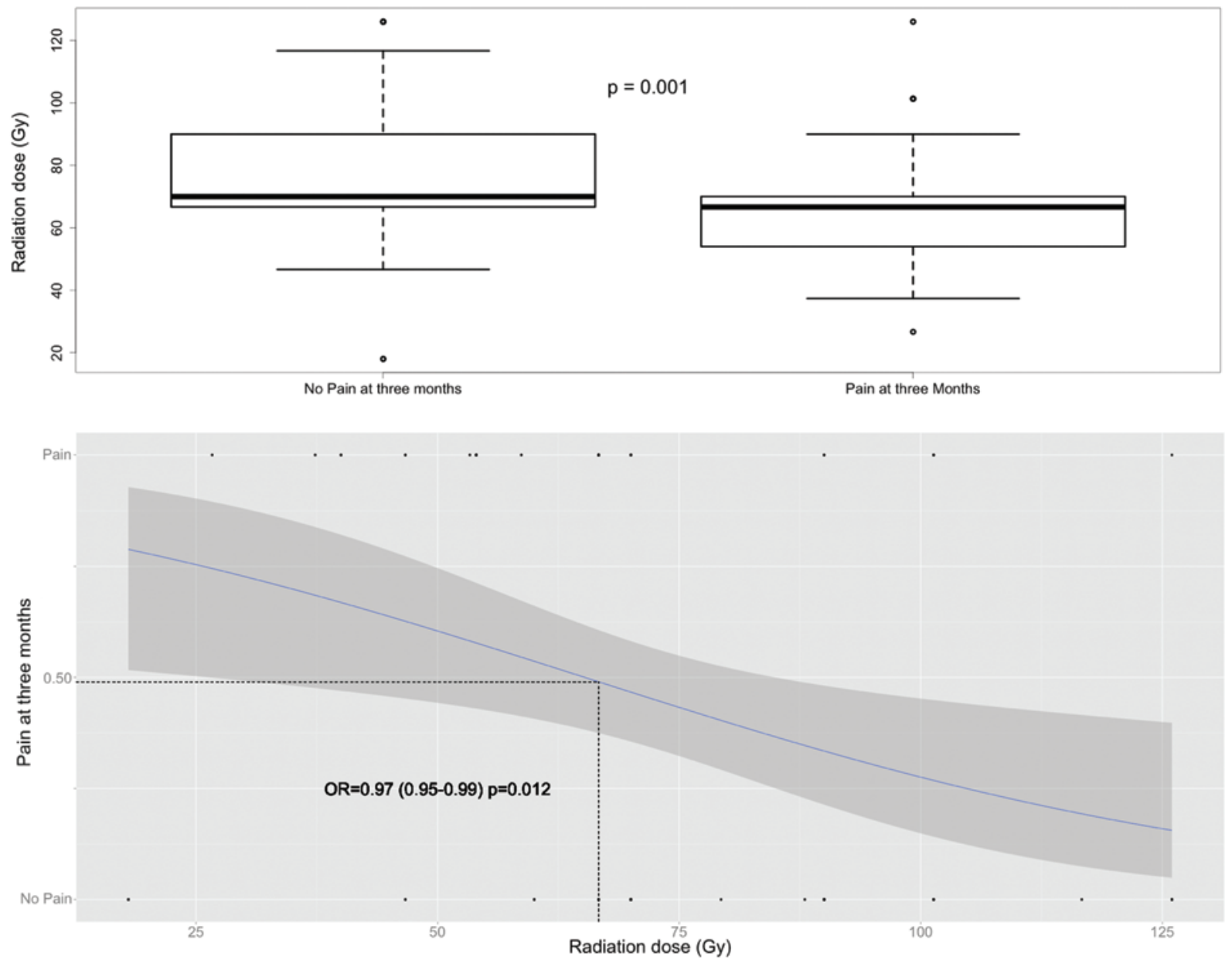

FIG. 3. Stratification of reported pain by BED. Upper: Box-and-whisker plot depicting the difference in BED between patients who reported pain at 3 months and those who did not. Lower: Scatter plot with logistic regression curve with confidence intervals showing the association between the radiation dose and the chances of having pain 3 months after treatment. Horizontal and vertical lines extending from a probability of 0.49 and a dose of $66.7 \mathrm{~Gy}$ are drawn to indicate the chosen threshold value. Figure is available in color online only.

canal impingement, rates of treatment success were higher for bone metastases that did not abut the spinal cord than for those that did contact the spinal cord. This finding is logical given the technical restrictions of SBRT and the need to meet strict cord tolerance doses during treatment planning. These data suggest that SBRT should be used with caution in patients with Bilsky Grade 1c or greater. This finding is consistent with that of a prior surgical series, which suggested that surgical decompression should be considered in patients with extensive epidural disease (i.e., Bilsky Grade 2 and higher) before treatment with SBRT. ${ }^{2}$ This concept has been previously described as separation surgery, or surgical circumferential decompression. ${ }^{22,39}$ A recent study by Laufer et al. reported durable local control with use of separation surgery before SBRT; patients included in that study often experienced significant progression of epidural disease before treatment (Bilsky Grade 2 or 3 lesions for more than 70\%), necessitating open surgical intervention. ${ }^{22}$

Our findings, combined with results from previous reports, suggest that surgical intervention should be considered as the first-line strategy for patients with disease in direct contact with the spinal cord, particularly in patients with instability or neurological deficits. ${ }^{29}$ The optimal radiosurgical management of patients with significant epidural extension represents an area in need of future investigation. Optimization of radiation treatment regimens may lead to improved outcomes in this patient population, a conclusion that is in accordance with the results of the multivariate analysis. Specifically, threshold values for BEDs will be an important focus. Our data suggest that patients with lesions receiving a minimum BED of 66.7 Gy (the median BED of this study) had a greater than 50\% chance of favorable pain outcomes 3 months after treatment.

The median prescribed dose in this series was $21 \mathrm{~Gy}$ delivered in 3 fractions, which is less aggressive than the doses reported for many other series..$^{13,26,35}$ In part, this difference results from the fact that many $(40.4 \%)$ of the patients included in our study had previously undergone received radiation therapy at the same site. For those patients, prescription doses were reduced to meet normal tissue constraints. In addition, we included patients from our initial experience with spine SBRT, and doses became 
TABLE 6. Summary of studies reported in the literature

\begin{tabular}{|c|c|c|c|c|c|}
\hline \multirow[b]{2}{*}{ Authors \& Year } & \multirow[b]{2}{*}{ Median Survival (mos) } & \multirow[b]{2}{*}{ 1-Yr Survival (\%) } & \multicolumn{2}{|c|}{ KPS Score } & \multirow[b]{2}{*}{ Mean Age or Range (yrs) } \\
\hline & & & $80-100$ & $50-70$ & \\
\hline Ahmed et al., 2012 & $>12$ & 52.2 & \multicolumn{2}{|c|}{ NP } & 56.8 \\
\hline Garg et al., 2012 & 30.4 & $80^{*}$ & 48 & 13 & $60 \dagger$ \\
\hline Patel et al., 2012 & 10.7 & NP & \multicolumn{2}{|c|}{ NP } & $57-62$ \\
\hline Wang et al., 2012 & 23 & 71.9 & 116 & 33 & 56.4 \\
\hline Sahgal et al., 2009 & 21 & $>50$ & 39 & $0 \ddagger$ & $57-59$ \\
\hline Garg et al., 2011 & 22.5 & 76 & 45 & 14 & $60 \dagger$ \\
\hline Gerstzen et al., 2007 & $>21 \S$ & $>50$ & \multicolumn{2}{|c|}{ NP } & 56 \\
\hline Gagnon et al., 2009 & $10.5-14.5$ & $\mathrm{NP}$ & \multicolumn{2}{|c|}{ NP } & 56 \\
\hline Chang et al., 2007 & 24 & $>60$ & 42 & 21 & $59 \dagger$ \\
\hline Heron et al., 2012 & 13 & $>50$ & \multicolumn{2}{|c|}{ NP } & 59 \\
\hline Koyfman et al., 2012 & 12.8 & $>50$ & \multicolumn{2}{|c|}{ Median 80} & $58.5 \dagger$ \\
\hline Yamada et al., 2008 & 15 & $>50$ & \multicolumn{2}{|c|}{ NP } & $62 \dagger$ \\
\hline Present study & 9.1 & 43.7 & 67 & $32 \pi$ & 60.4 \\
\hline \multicolumn{6}{|c|}{$\begin{array}{l}\text { NP = not presented in the article. } \\
\text { * Approximate values determined from Kaplan-Meier curves. } \\
\text { † Mean ages were not available; reported values were median ages. } \\
\text { Ғ KPS scores were all } 70 \text { or above in this cohort; no further information was provided. } \\
\S \text { Median follow-up time was } 21 \text { months; it can be assumed that median survival time was at least this long. } \\
\text { † For } 1 \text { patient, the reported KPS score was } 40 \text {. }\end{array}$} \\
\hline
\end{tabular}

more aggressive as the experience of providers and confidence in the safety and reproducibility of the technique increased. At present, we aim to treat patients with the most hypofractionated dose schedule that allows for adequate tumor coverage while meeting normal tissue constraints. Several factors play into the decision, including tumor size and distance from critical structures such as the spinal cord and esophagus.

We report no cases of radiation-induced spinal cord myelopathy. We also report a $7.0 \%$ risk for de novo vertebral compression fractures, consistent with rates reported in prior studies $(6.6 \%-11.0 \%) .5,10,35$ More aggressive dosing paradigms, such as single fraction doses above $20 \mathrm{~Gy}$, have been associated with a higher risk for compression fractures. ${ }^{35}$ However, higher BEDs may be associated with improved local control, and the current practice at our institution is to use more aggressive fractionation schedules than is reflected by the median reported in this series; many of these patients had received prior overlapping external beam radiation therapy.

Our study has several limitations. First, the primary outcome assessed in this study was local pain at the treated vertebral level, a parameter that is challenging to assess in a retrospective manner. To address this problem, data points corresponding to pain were collected only when clinical notes directly mentioned whether the patient had pain and thus pain was scored in a binary manner. Another key limitation was that many of our patients were lost to follow-up, preventing outcome assessment for all patients. This limitation applies especially to radiological outcomes, because most patients, unfortunately, did not undergo serial follow-up MRI. Last, to compare the wide variety of radiation dose prescriptions, we used the linear-quadratic BED estimation model. The accuracy of this model is questioned for doses per fraction outside the range of 2-10 Gy. ${ }^{6}$ Nonetheless, in the absence of an alternative measure, the use of BED was our best method for comparing the wide variety of dose and fractionation schedules included in our analyses. However, the threshold BED (with an $\alpha / \beta$ of 3.0) dose derived in this study should be viewed with caution and merits further investigation.

This study investigates a heterogeneous study population characterized by many different tumor histologic types and radiation treatment schemes. Future studies with more controlled treatment regimens that focus on specific pathologies are needed.

\section{Conclusions}

Stereotactic radiosurgery is a well-accepted management option for spinal metastases in patients with advanced metastatic disease. Pain palliation occurs as early as 3 months, and significant differences in pain also occur at 6 and 12 months. The data presented in this article suggest more limited pain palliation for patients with tumors with epidural extension that deforms the cord or for patients who have previously received radiation to the same site. Further investigation into optimal doses and fractionation schedules is needed, but we report improved outcome in patients receiving a BED of 66.7 Gy or higher.

\section{References}

1. Ahmed KA, Stauder MC, Miller RC, Bauer HJ, Rose PS, Olivier KR, et al: Stereotactic body radiation therapy in spinal metastases. Int J Radiat Oncol Biol Phys 82:e803-e809, 2012

2. Al-Omair A, Masucci L, Masson-Cote L, Campbell M, Atenafu EG, Parent A, et al: Surgical resection of epidural disease improves local control following postoperative spine stereotactic body radiotherapy. Neuro Oncol 15:1413-1419, 2013 
3. Bilsky MH, Laufer I, Fourney DR, Groff M, Schmidt MH, Varga PP, et al: Reliability analysis of the epidural spinal cord compression scale. J Neurosurg Spine 13:324-328, 2010

4. Bilsky MH, Yamada Y, Yenice KM, Lovelock M, Hunt M, Gutin PH, et al: Intensity-modulated stereotactic radiotherapy of paraspinal tumors: a preliminary report. Neurosurgery 54:823-831, 2004

5. Boehling NS, Grosshans DR, Allen PK, McAleer MF, Burton AW, Azeem S, et al: Vertebral compression fracture risk after stereotactic body radiotherapy for spinal metastases. J Neurosurg Spine 16:379-386, 2012

6. Brenner DJ: The linear-quadratic model is an appropriate methodology for determining isoeffective doses at large doses per fraction. Semin Radiat Oncol 18:234-239, 2008

7. Buccheri G, Ferrigno D, Tamburini M: Karnofsky and ECOG performance status scoring in lung cancer: a prospective, longitudinal study of 536 patients from a single institution. Eur J Cancer 32A:1135-1141, 1996

8. Chang EL, Shiu AS, Mendel E, Mathews LA, Mahajan A, Allen PK, et al: Phase I/II study of stereotactic body radiotherapy for spinal metastasis and its pattern of failure. $\mathbf{J}$ Neurosurg Spine 7:151-160, 2007

9. Cobb CA III, Leavens ME, Eckles N: Indications for nonoperative treatment of spinal cord compression due to breast cancer. J Neurosurg 47:653-658, 1977

10. Cunha MV, Al-Omair A, Atenafu EG, Masucci GL, Letourneau D, Korol R, et al: Vertebral compression fracture (VCF) after spine stereotactic body radiation therapy (SBRT): analysis of predictive factors. Int J Radiat Oncol Biol Phys 84:e343-e349, 2012

11. Faul CM, Flickinger JC: The use of radiation in the management of spinal metastases. J Neurooncol 23:149-161, 1995

12. Gagnon GJ, Nasr NM, Liao JJ, Molzahn I, Marsh D, McRae $\mathrm{D}$, et al: Treatment of spinal tumors using cyberknife fractionated stereotactic radiosurgery: pain and quality-of-life assessment after treatment in 200 patients. Neurosurgery 64:297-307, 2009

13. Garg AK, Shiu AS, Yang J, Wang XS, Allen P, Brown BW, et al: Phase $1 / 2$ trial of single-session stereotactic body radiotherapy for previously unirradiated spinal metastases. Cancer 118:5069-5077, 2012

14. Garg AK, Wang XS, Shiu AS, Allen P, Yang J, McAleer MF, et al: Prospective evaluation of spinal reirradiation by using stereotactic body radiation therapy: The University of Texas MD Anderson Cancer Center experience. Cancer 117:35093516, 2011

15. Gerszten PC, Burton SA, Ozhasoglu C, Welch WC: Radiosurgery for spinal metastases: clinical experience in 500 cases from a single institution. Spine (Phila Pa 1976) 32:193-199, 2007

16. Gerszten PC, Welch WC: Cyberknife radiosurgery for metastatic spine tumors. Neurosurg Clin N Am 15:491-501, 2004

17. Gokaslan ZL, York JE, Walsh GL, McCutcheon IE, Lang FF, Putnam JB Jr, et al: Transthoracic vertebrectomy for metastatic spinal tumors. J Neurosurg 89:599-609, 1998

18. Heron DE, Rajagopalan MS, Stone B, Burton S, Gerszten PC, Dong X, et al: Single-session and multisession CyberKnife radiosurgery for spine metastases-University of Pittsburgh and Georgetown University experience. J Neurosurg Spine 17:11-18, 2012

19. Ibrahim A, Crockard A, Antonietti P, Boriani S, Bünger C, Gasbarrini A, et al: Does spinal surgery improve the quality of life for those with extradural (spinal) osseous metastases? An international multicenter prospective observational study of 223 patients. J Neurosurg Spine 8:271-278, 2008

20. Kaloostian PE, Yurter A, Zadnik PL, Sciubba DM, Gokaslan ZL: Current paradigms for metastatic spinal disease: an evidence-based review. Ann Surg Oncol 21:248-262, 2014
21. Koyfman SA, Djemil T, Burdick MJ, Woody N, Balagamwala $\mathrm{EH}$, Reddy CA, et al: Marginal recurrence requiring salvage radiotherapy after stereotactic body radiotherapy for spinal metastases. Int J Radiat Oncol Biol Phys 83:297-302, 2012

22. Laufer I, Iorgulescu JB, Chapman T, Lis E, Shi W, Zhang Z, et al: Local disease control for spinal metastases following "separation surgery" and adjuvant hypofractionated or highdose single-fraction stereotactic radiosurgery: outcome analysis in 186 patients. J Neurosurg Spine 18:207-214, 2013

23. Lenz M, Freid JR: Metastases to the skeleton, brain and spinal cord from cancer of the breast and the effect of radiotherapy. Ann Surg 93:278-293, 1931

24. Levack P, Graham J, Collie D, Grant R, Kidd J, Kunkler I, et al: Don't wait for a sensory level-listen to the symptoms: a prospective audit of the delays in diagnosis of malignant cord compression. Clin Oncol (R Coll Radiol) 14:472-480, 2002

25. Milker-Zabel S, Zabel A, Thilmann C, Schlegel W, Wannenmacher M, Debus J: Clinical results of retreatment of vertebral bone metastases by stereotactic conformal radiotherapy and intensity-modulated radiotherapy. Int $\mathbf{J}$ Radiat Oncol Biol Phys 55:162-167, 2003

26. Moulding HD, Elder JB, Lis E, Lovelock DM, Zhang Z, Yamada Y, et al: Local disease control after decompressive surgery and adjuvant high-dose single-fraction radiosurgery for spine metastases. J Neurosurg Spine 13:87-93, 2010

27. Nielsen OS, Munro AJ, Tannock IF: Bone metastases: pathophysiology and management policy. J Clin Oncol 9:509-524, 1991

28. Ortiz Gómez JA: The incidence of vertebral body metastases. Int Orthop 19:309-311, 1995

29. Patchell RA, Tibbs PA, Regine WF, Payne R, Saris S, Kryscio RJ, et al: Direct decompressive surgical resection in the treatment of spinal cord compression caused by metastatic cancer: a randomised trial. Lancet 366:643-648, 2005

30. Patel VB, Wegner RE, Heron DE, Flickinger JC, Gerszten P, Burton SA: Comparison of whole versus partial vertebral body stereotactic body radiation therapy for spinal metastases. Technol Cancer Res Treat 11:105-115, 2012

31. Ryken TC, Eichholz KM, Gerszten PC, Welch WC, Gokaslan ZL, Resnick DK: Evidence-based review of the surgical management of vertebral column metastatic disease. Neurosurg Focus 15(5):E11, 2003

32. Ryu S, Fang Yin F, Rock J, Zhu J, Chu A, Kagan E, et al: Image-guided and intensity-modulated radiosurgery for patients with spinal metastasis. Cancer 97:2013-2018, 2003

33. Ryu SI, Chang SD, Kim DH, Murphy MJ, Le QT, Martin DP, et al: Image-guided hypo-fractionated stereotactic radiosurgery to spinal lesions. Neurosurgery 49:838-846, 2001

34. Sahgal A, Ames C, Chou D, Ma L, Huang K, Xu W, et al: Stereotactic body radiotherapy is effective salvage therapy for patients with prior radiation of spinal metastases. Int J Radiat Oncol Biol Phys 74:723-731, 2009

35. Sahgal A, Atenafu EG, Chao S, Al-Omair A, Boehling N, Balagamwala $\mathrm{EH}$, et al: Vertebral compression fracture after spine stereotactic body radiotherapy: a multi-institutional analysis with a focus on radiation dose and the spinal instability neoplastic score. J Clin Oncol 31:3426-3431, 2013

36. Sundaresan N, Krol G, DiGiacinto GV: Metastatic tumors of the spine, in Sundaresan N, Schmidek H, Schiller AL, et al (eds): Tumors of the Spine: Diagnosis and Clinical Management. Philadelphia: WB Saunders, 1990

37. Swenerton KD, Legha SS, Smith T, Hortobagyi GN, Gehan EA, Yap HY, et al: Prognostic factors in metastatic breast cancer treated with combination chemotherapy. Cancer Res 39:1552-1562, 1979

38. Tomita K, Kawahara N, Kobayashi T, Yoshida A, Murakami H, Akamaru T: Surgical strategy for spinal metastases. Spine (Phila Pa 1976) 26:298-306, 2001

39. Wang JC, Boland P, Mitra N, Yamada Y, Lis E, Stubblefield 
M, et al: Single-stage posterolateral transpedicular approach for resection of epidural metastatic spine tumors involving the vertebral body with circumferential reconstruction: results in 140 patients. J Neurosurg Spine 1:287-298, 2004

40. Wang XS, Rhines LD, Shiu AS, Yang JN, Selek U, Gning I, et al: Stereotactic body radiation therapy for management of spinal metastases in patients without spinal cord compression: a phase 1-2 trial. Lancet Oncol 13:395-402, 2012

41. Wong DA, Fornasier VL, MacNab I: Spinal metastases: the obvious, the occult, and the impostors. Spine (Phila Pa 1976) 15:1-4, 1990

42. Yamada Y, Bilsky MH, Lovelock DM, Venkatraman ES, Toner S, Johnson J, et al: High-dose, single-fraction imageguided intensity-modulated radiotherapy for metastatic spinal lesions. Int J Radiat Oncol Biol Phys 71:484-490, 2008

\section{Author Contributions}

Conception and design: Lim, Puvanesarajah, Bydon, Redmond.
Acquisition of data: Lim, Puvanesarajah, Aygun, Bydon, Rigamonti, Kleinberg, Redmond. Analysis and interpretation of data: Lim, Puvanesarajah, Aygun, Jusué-Torres, Bydon, Redmond. Drafting the article: Puvanesarajah, Jusué-Torres, Elder. Critically revising the article: Lim, Puvanesarajah, Lo, Aygun, Liauw, Jusué-Torres, Lina, Elder, Bydon, Bettegowda, Kleinberg,

Witham, Redmond. Reviewed submitted version of manuscript: Lim, Puvanesarajah, Lo, Aygun, Liauw, Lina, Hadelsberg, Elder, Bydon, Bettegowda, Sciubba, Wolinsky, Rigamonti, Kleinberg, Gokaslan, Witham, Redmond. Statistical analysis: Puvanesarajah, Jusué-Torres. Study supervision: Lim, Puvanesarajah, Bydon, Redmond.

\section{Correspondence}

Michael Lim, Department of Neurosurgery, The Johns Hopkins Hospital, 600 N. Wolfe St., Phipps, Rm. 123, Baltimore, MD 21287. email: mlim3@jhmi.edu. 